2. Nonaka M, Kadokura M, Kataoka D, Yamamoto S, Tanio N, Iyano K, et al. Surgically treated infectious giant bulla (in Japanese with English abstract). Jpn J Thorac Surg. 2000;53:880-2.

3. Stone DJ, Schwartz A, Feltman JA. Bullous emphysema: a long-term study of the natural history and the effects of therapy. Am Rev Respir Dis. 1960; 82:493-507.
4. Nomori H, Horio H, Fuyuno G, Kobayashi R, Morinaga S, Suemasu K. Opening of infectious giant bulla with use of video-assisted thoracoscopic surgery. Chest. 1997;112:1670-3.

5. Verma RK, Nishiki M, Mukai M, Fujii T, Kuranishi F, Yoshioka S, et al. Intracavitary drainage procedure for giant bullae in compromised patients. Hiroshima J Med Sci. 1991;40:115-8

\title{
Incomplete transmural ablation caused by bipolar radiofrequency ablation devices
}

\author{
Wataru Kato, MD, Akihiko Usui, MD, Hideki Oshima, MD, Toshiaki Akita, MD, and Yuichi Ueda, MD, Nagoya, Japan
}

Since the recent development of radiofrequency ablation devices, surgical ablation of atrial fibrillation has become more common. ${ }^{1-4}$ We have recently adopted the Atricure bipolar radiofrequency clamp (Atricure, Inc, Cincinnati, Ohio) for surgical ablation. According to some reports, a bipolar radiofrequency system ensures transmurality compared with the unipolar system. ${ }^{1,2}$ However, even when using a bipolar device an incomplete ablation can occur as a result of the thickness of the atrium wall or folding on itself $f^{2-4}$ and thus can trigger a recurrence of atrial fibrillation. Because the pathologic sections of ablation lesions were occasionally obtained from an autopsy patient, we report a case of an incomplete ablation of the left atrium.

\section{CLINICAL SUMMARY}

An 81-year-old man with aortic regurgitation and atrial fibrillation electively underwent aortic valve replacement and the left atrial maze procedure by using the Atricure clamp through a median sternotomy. The ablation was performed circumferentially on the orifice of the right and left pulmonary veins and the neck of the left atrial appendage by using the Atricure bipolar radiofrequency clamp during cardiac arrest. Each ablation was done twice to ensure transmurality. The generator of the radiofrequency device showed low and stabilized tissue conductance each time. After completing the ablation, the left atrial appendage was ligated. Cryoablation was also applied on the right atrium between the coronary sinus and isthmus of the inferior vena cava, and the aortic valve was then replaced with the $23-\mathrm{mm}$ Med-

\footnotetext{
From the Department of Cardiothoracic Surgery, Nagoya University Graduate School of Medicine, Nagoya, Japan.

Received for publication Jan 24, 2008; revisions received Feb 15, 2008; accepted for publication March 2, 2008.

Address for reprints: Wataru Kato, MD, Department of Cardiothoracic Surgery, Nagoya University Graduate School of Medicine, 65, Tsurumai-cho, Showa-ku, Nagoya, Aichi 466-8550, Japan (E-mail: kwataru@med.nagoya-u.ac.jp).

J Thorac Cardiovasc Surg 2009;137:251-2

0022-5223/\$36.00

Copyright (c) 2009 by The American Association for Thoracic Surgery

doi:10.1016/j.jtcvs.2008.03.004
}

tronic Mosaic bioprosthesis (Medtronic, Inc, Minneapolis, Minn). The atrial fibrillation was converted into normal sinus rhythm after resuming the heartbeat. Early after surgical intervention, the patient once had a paroxysmal atrial fibrillation that was easily converted into normal sinus rhythm with medication. Except for this episode, the postoperative course had been uneventful until the third postoperative day. However, the patient had a mesenteric ischemia abruptly and died on the fifth postoperative day. A pathologic autopsy revealed massive intestinal necrosis. Because cardiogenic thromboembolisms were suspected, lesions of the radiofrequency ablation were also dissected to rule out the left atrial thrombus related to surgical ablation. The lesions were easily detected because of discoloration of the intima. On microscopic examination, the lesion of the neck of the atrial appendage showed transmural scar tissue, suggesting that the transmural ablation was complete (Figure 1). However, another section of the posterior wall of the left atrium showed an incomplete transmural ablation. Microscopic findings showed that the intima was thickened, probably by the ablation, but the normal myocardium of the left atrium partially remained among necrotic tissue on the thick atrial wall (Figure 2). No thrombus was found in the heart. The mesenteric arteries also revealed no thromboembolism. The pathologic diagnosis was nonobstructive mesenteric ischemia.

\section{DISCUSSION}

The clinical effectiveness of bipolar ablation devices has been reported. ${ }^{1-4}$ Bipolar devices have 2 jaws equipped with electrodes. By clamping the atrial tissue between the jaws, radiofrequency energy is delivered effectively to the tissue, and more precise transmural ablation is obtained than with unipolar types of devices. Because the conductance of the tissue clamped between the jaws of the device relates to the transmurality of ablation, the bipolar devices measure the tissue conductance between the jaws. A low and stabilized conductance is used as an indicator of transmural ablation. ${ }^{1}$ 


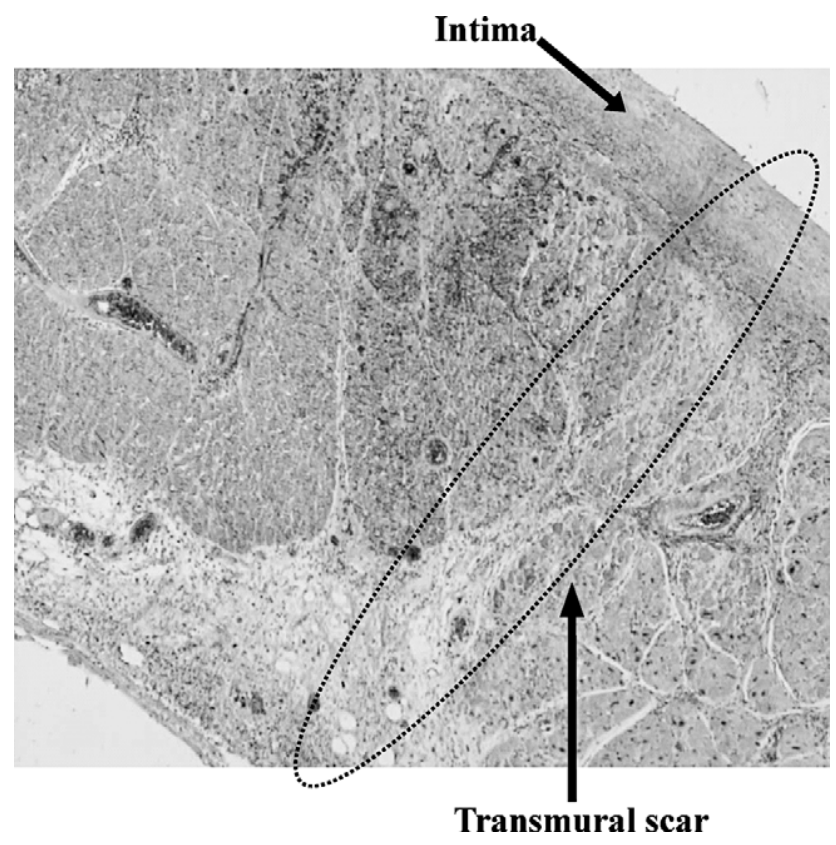

FIGURE 1. A microscopic section revealed that myocardium of the lesion disappeared and transmural ablation was completed (hematoxylin and eosin stain).

However, cases have been reported in which the transmural ablation could not always be completed because of atrial wall thickness or folding in on itself, even when the generator of the device shows a low and stabilized tissue conductance. $^{2-4}$ Therefore some surgeons recommend repeated clump applications to ensure transmurality. ${ }^{3,4}$ In line with such reports, we also made it a practice to apply the clamp twice on each lesion. However, an incomplete transmural lesion was observed. In fact, the patient's rhythm was successfully converted into normal sinus rhythm. However, the patient had paroxysmal atrial fibrillation after surgical intervention. The incomplete ablation might have caused the recurrence. Wall thickness is sometimes observed, and an inappropriate application can take place as a result of folding of the atrial wall, particularly in the posterior wall of the left atrium during pulmonary vein isolations. Pacing on pulmo-

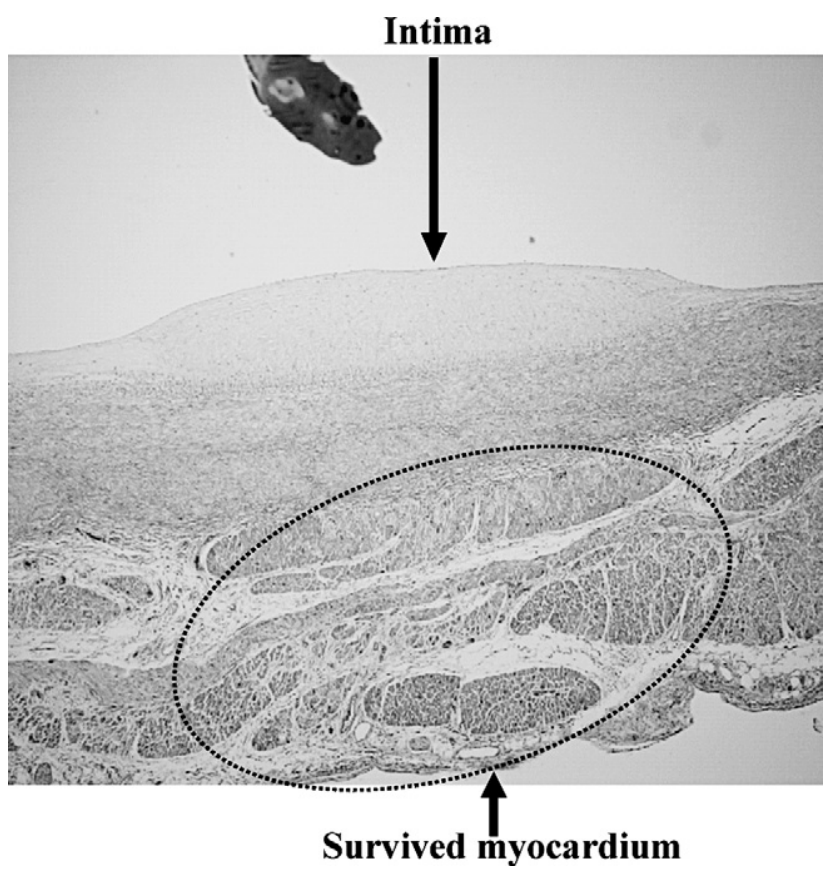

FIGURE 2. A microscopic section showed an incomplete transmural ablation. The thickened intima was observed, and the normal myocardium of the left atrium was partially remained (hematoxylin and eosin stain).

nary veins is a good way to confirm whether conduction block is obtained, and repeated ablation reduces the risk of incomplete ablation. ${ }^{1,3}$ Therefore we strongly recommend that all lesions should be tested by pacing on pulmonary veins to ensure complete surgical ablation.

\section{References}

1. Prasad SM, Maniar HS, Schuessler RB, Damiano Jr RJ Chronic transmural atrial ablation by using bipolar radiofrequency energy on the beating heart. J Thorac Cardiovasc Surg. 2002;124:708-13.

2. Bugge E, Nicholson IA, Thomas SP. Comparison of bipolar and unipolar radiofrequency ablation in an in vivo experimental model. Eur $J$ Cardiothorac Surg. 2005;28:76-82.

3. Gillinov AM, McCarthy PM. Atricure bipolar radiofrequency clamp for intraoperative ablation of atrial fibrillation. Ann Thorac Surg. 2002;74:2165-8.

4. Benussi S, Nascimbene S, Calori G, Denti P, Ziskind Z, Kassem S, et al. Surgical ablation of atrial fibrillation with a novel bipolar radiofrequency device. $J$ Thorac Cardiovasc Surg. 2005;130:491-7. 